\title{
Halfeti Gülü (Rosa odorata 'Louis XIV') ve farklı gül taksonlarının bazı pomolojik ve fizyolojik özellikleri
}

\section{Some pomological and physiological characteristics of Halfeti Rose (Rosa odorata 'Louis $\left.X I V^{\prime}\right)$ and different rose taxa}

\author{
İbrahim Halil HATiPOĞLU1*iD, Bekir Erol AK \\ ${ }^{1}$ Harran Üniversitesi, Fen Bilimleri Enstitüsü, Bahçe Bitkileri Anabilim Dalı, Şanlıurfa \\ ${ }^{2}$ Harran Üniversitesi, Ziraat Fakültesi, Bahçe Bitkileri Bölümü, Şanlıurfa \\ ${ }^{1}$ https://orcid.org/0000-0002-7236-4976; ${ }^{2}$ https://orcid.org/0000-0001-6938-942X
}

\section{To cite this article:}

Hatipoğlu, i. \& Ak, B. (2021). Halfeti Gülü (Rosa odorata 'Louis XIV') ve farklı gül taksonlarının bazı pomolojik ve fizyolojik özellikleri. Harran Tarım ve Gıda Bilimleri Dergisi, 25(4): 457468.

DOI: 10.29050/harranziraat.980733

*Address for Correspondence: Ibrahim Halil HATIPOĞLU e-mail:

ibrahimhhatipoglu@gmail.com

Received Date:

09.08.2021

Accepted Date:

18.11.2021

(C) Copyright 2018 by Harran University Faculty of Agriculture. Available on-line at www.dergipark.gov.tr/harranziraat

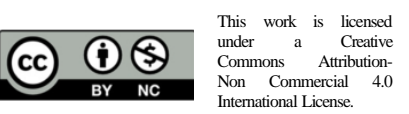

Öz

Bu çalışmada, Halfeti Gülü ile bazı yabani, eski bahçe gülü ve modern güllerin ( $R$. hemisphaerica J.Herrmann, $R$. chinensis Jacquin 'Old Blush', $R$.canina L. 'Yıldız', R. pisiformis (Christ) D.Sosn., R. foetida J.Herrmann., R. heckeliana Tratt., $R$. damascena Miller ve R. alba L.) bazı pomolojik ve fizyolojik özelliklerinin ortaya çıkarılarak karşılaştırılması amaçlanmıştır. Halfeti Gülü’nün genelde kesme çiçekçilik veya kuru gül amacı ile kullanılması sebebi ile meyve oluşmadan çiçekleri hasat edilmekte ve pomolojik (meyve) özellikleri ile ilgili bir veri bulunmamaktadır. Bu çalışma kapsamında hem Halfeti Gülü meyveleri ile ülkemizde yaygın olarak Van ve Tokat bölgelerinde yayılış gösteren kuşburnu meyveleri ile karşılaştırılmış hem de 9 farklı gül taksonunun yaprak oransal su kapsamı, stoma yoğunluğu ve klorofil içeriği gibi fizyolojik verileri ortaya konulmuştur. Halfeti Gülü’nün yaprak oransal su kapsamı oranının düşük bulunması (40.30\%) dikkat çekicidir. Halfeti Gülü'nün sadece belli bir lokasyonda 'koyu siyah' taç yaprak rengi alması yaprak oransal su kapsamı, stoma yoğunluğu ve klorofil içeriği gibi değerler ve abiyotik stres koşulları ile ilişkilendirilebilmekte, bu verilerin bilinmesinin peyzaj planlama ve tasarım çalışmalarında sürdürülebilir ve planlı bir bitki kullanımına olanak sağlayacağı düşünülmektedir.

Anahtar Kelimeler: Halfeti Gülü, Gül, Kuşburnu, Pomoloji, Fizyoloji

\section{ABSTRACT}

In this study, Halfeti Rose and some wild, old garden roses and modern roses ( $R$. hemisphaerica J.Herrmann, $R$. chinensis Jacquin 'Old Blush', R. canina L. 'Yıldız', R. pisiformis (Christ) D.Sosn ., R. foetida J.Herrmann., R. heckeliana Tratt., R. damascena Miller, and R. alba L.) some pomological and physiological characteristics were revealed and compared. Since Halfeti Rose is generally used for cut floriculture or dried roses, its flowers are harvested before fruit is formed and there is no data on its pomological (fruit) properties. Within the scope of this study, both Halfeti Rose fruits and rosehip fruits widely distributed in Van and Tokat regions in our country were compared and physiological data such as leaf proportional water content, stomatal density and chlorophyll content of 9 different rose taxa were revealed. It is noteworthy that the leaf proportional water content rate of Halfeti Rose is low (40.30\%). The 'dark black' petal color of Halfeti Rose only in a certain location can be associated with values such as leaf proportional water content, stomatal density and chlorophyll content and abiotic stress conditions. is thought to provide.

Key Words: Halfeti Rose, Rose, Rosehips, Pomology, Physiology 


\section{Giriş}

Türkiye, gül (Rosa L.) cinsi için önemli bir gen merkezidir. Dünya üzerinde yayılış gösteren ve 0 ile 3000 metre gibi geniş bir yükselti aralığında yayılış gösteren güllerin yaklaşık \%25'i Türkiye'ye özgüdür. Anadolu'da çok sayıda yabani gül türü bulunmakta olup sistematik açıdan sınıflandırma zorluğu ortadadır. Poliploidi ve hibritleşme gibi nedenler ile doğal gül taksonu için kesin bir sayı verilememektedir. $R$. gallica, $R$. damascena ve $R$. alba gibi bazı gül türlerinin çiçekleri Anadolu'da uzun süredir gül yağı ve gül suyu üretiminde kullanılmaktadır. Diğer bazı türlerin meyveleri (kuşburnu) ekonomik değere sahiptir ve tıbbi amaçlar için de kullanılmaktadır (Ercisli, 2005; Korkmaz ve Özçelik, 2015).

Parklarda, bahçelerde veya saksılarda her yıl milyonlarca gül yetiştirilirken, aynı zamanda ticari amaçlarla da sayısız kesme gül kullanılmaktadır. Tüketici tercihi ön planda tutularak her yıl yüzlerce çeşit gül piyasaya arz edilmektedir. Kesme güllerde yeni bir çeşit ıslah etmek 4-6 yıl, peyzaj güllerinde ise 8-10 yıl sürmektedir (Karagüzel ve ark., 2014).

Türkiye meyvecilik konusunda köklü bir kültüre sahip olmasına rağmen kuşburnu konusunda standart çeşitler üzerindeki çalışmalar 2000'li yıllarda başlamıştır. Gül/kuşburnu meyvesi yetiştiriciliğinde çeşit veya tipleri belirsiz bitkilerden meyve elde edilmesi belli bir standardın sağlanmasını engellemektedir. Bu bağlamda ıslah çalışmaları açısından da önemli olan bu türlerin meyveciliğe kazandırılması gerekmektedir. Gül çeşitlerinde tüketicilerin talepleri, ticari değerlendirilme şekilleri (gıda ilaç sanayi vb.), yetiştiricilik yapılan yörenin ekolojik uygunluğu gibi birçok etkene bağlı olarak oldukça geniş bir çeşitlilik göstermektedir. Özellikle kırmızı meyvelerin yüksek miktarda biyoaktif bileşik kaynakları olarak belirlenmiştir (Özden ve ark., 2017). Sanayiye uygun kuşburnu çeşidinin geliştirilmesinde iri ve meyve eti oranı yüksek çeşitler tercih edilmektedir (Çelik ve ark., 2009). Türkiye'de 'Yıldız' (Anonim, 2012) ve 'Gerçekçioğlu' (Anonim, 2015; Gerçekçioğlu ve Öz
Atasever, 2017) gibi kuşburnu çeşitlerinin tescil edildiği bilinmektedir (Kınık ve Çelikel, 2020).

$R$. odorata bitkisi son zamanlarda reçel, gül suyu gibi evsel ihtiyaçların üretiminde kullanılmaktadır. Yediveren çeşitleri ve fındık güllerinin önemli bir kısmı bu taksona ait olup, Güneydoğu Anadolu Bölgesi ve Suriye'nin kuzeyinde birçok genotipi bulunmaktadır. Eski bahçe gülü olarak adlandırılabilecek bu genotipler genelde gül suyu üretimi ve kuru gül amacı ile yetiştirilmektedir (Özçelik, 2013). R. odorata 'Louis XIV' çeşidi, Halfeti gülü olarak bilinen, çiçekleri büyük, genelde tekli, taç yaprakların ortasında beyaz çizgi bulunan, tomurcuk halinde koyu, çiçekler açıldıktan sonra sıcaklığın etkisi ile antosiyanin pigmentinin azalması ile rengi bordoya dönen hoş kokulu bir peyzaj gülüdür (Baytop, 2001; Özden, 2013; Özçelik, 2018; Özçelik ve Koca, 2021).

Bilinen genel kanının aksine $R$. odorata endemik bir tür değildir. Fakat bu türün kültivarı olan Halfeti Gülü, Şanlıurfa ili Halfeti ilçesinin ekolojik koşullarında en koyu rengi alması nedeni ile bu il ve ilçe ile özdeşleşmiştir. Yetiştirildiği ekolojik koşullarda yaz mevsiminde kırmızı iken geç sonbaharda çiçek renginin siyaha yakın koyu kırmızıya dönüştüğü belirtilmiştir (Özden, 2013).

Coğrafi işaretler, açıkça belli bir niteliği veya diğer özellikleri itibariyle kökeninin bulunduğu lokasyon ile özdeşleşmiş bir ürünü gösteren işaretlerdir (Şahin ve Meral, 2012). Bu bağlamda; söz konusu tanıma uyduğu belirtilen Halfeti Gülü, kırsal turizme, kırsal nüfusun farklı iş alanlarına yönelmesine katkı sağlaması amacı ile 2021 yılında coğrafi işaret almıştır (Anonim, 2021). Ayrıca gelişmiş ülkeler, 1990'lı yılların başından bu yana birçok çiçek türünün üretim alanını mali sebepler ile uygun iklim koşullarının olduğu ülkelere kaydırmaya başlamış, bu ülkelerden üretim materyali (çelik vb.) alma yolunu tercih etmişlerdir (Kazaz ve ark., 2015).

Halfeti Gülü'nün taç yaprakları genelde kurutularak değerlendirildiği için meyve oluşmadan çiçekleri hasat edilmektedir. Ayrıca bu tür üzerinde pomolojik çalışmalar yapılmadığı için söz konusu türün meyve özellikleri ile ilgili bir bilgi 
bulunmamaktadır.

2021 yılında Türkiye'de meydana gelen yangınlarda birçok alanda bitki kayıpları yaşanmıştır. Bu alanların bitkilendirilmesinde de güller önemlidir. Bu alanlarda ekolojik koşullara adapte olmuş gül türleri önemli bir bitkisel materyal olarak değerlendirilebilir. Bazıları ise meyveleri ve çiçekleri ile ilaç ve gıda sanayisinde kullanılabilmektedir. Bu bağlamda; bazı yaprak parametrelerinin ve meyve özelliklerinin belirlenmesinin gülün ekonomik değerini ortaya koyacağı düşünülmektedir.

Çalışma kapsamında, Halfeti Gülü meyveleri ile ülkemizde Van ve Tokat yörelerinde yaygın olarak yayılıs gösteren lokasyonlardan alınan kuşburnu meyvelerinin karşılaştırması yapılmıştır. Çalışmada aynı zamanda söz konusu 8 takson çelik ile çoğaltılmış ve aynı ekolojik koşullarda yetiştirilerek fizyolojik özellikleri karşılaştırılmış, bu taksonların ekolojik koşullara adapte olmasında irdelenecek parametreleri belirlemek ve meyve özelliklerini karakterize etmek amaçlanmıştır.

\section{Materyal ve Yöntem}

Çalışmanın bitkisel materyallerini $R$. odorata 'Louis XIV' (Halfeti Gülü) bitkisi ile $R$. hemisphaerica (Çardak Gülü), R. chinensis 'Old Blush', R. canina 'Yıldız', R. pisiformis (Hoşap Gülü), R. foetida (Sarıgül), R. heckeliana (Şurubi Gül), R. damascena (Yağ gülü, Isparta Gülü) ve R.alba (Beyazgül) taksonları oluşturmaktadır. Şanlıurfa koşullarında yetişen güllerin meyvelerin parametrelerinin (meyve ağırlığı, meyve boyu, meyve eni, çekirdek sayısı, meyve et ağırlığı, meyve rengi) belirlenmesi için söz konusu taksonların meyve türlerinin iyi yetiştiği lokasyonlardan (Tokat, Van) kuşburnu örnekleri alınmıştır. Bitkisel materyaller; Halfeti Belediyesi Karagül Teşhir Serası'ndan (R. odorata 'Louis XIV'), Harran Üniversitesi Arboretumu AR-GE Serası'ndan (R. chinensis 'Old Blush'), Van Yüzüncü Yıl Üniversitesi Mimarlık ve Tasarım Fakültesi Peyzaj Mimarlığı Bölümü Araştırma Alanlarından ( $R$. hemispharica, $R$. pisiformis, $R$. foetida, $R$. heckeliana, R. alba, R. damascena) ve Tokat Gaziosmanpaşa Üniversitesi Ziraat Fakültesi Bahçe Bitkileri Bölümü Araştırma Alanlarında bulunan koleksiyon parselinden ( $R$. canina 'Yıldız') temin edilmiştir. Türlerin ve alt türlerin bilimsel adlarının (kısaltmalar (otörler) da dahil olmak üzere standart biçimiyle) yazımı için Brummitt ve Powell (1992) literatürü baz alınmıştır.

Yaprak özelliklerinin belirlenmesi amacı ile söz konusu bitkilerden 2019 yılında alınan çelikler Mart ayında Harran Üniversitesi Arboretumu ARGE serasında hacimsel olarak 1:1 torf ve toprak karışımı bulunan kasalara dikilmiştir. Dikim için yeterli kök yapısına ulaşan çelikler torf ve çiftlik gübresi (1:1) bulunan 5 litrelik saksılara şaşırtılmış ve sera koşullarında günde 3 defa sisleme (mist) yöntemi ile sulanmıştır. 2021 yılı itibari ile bu bitkilerde bazı yaprak özelliklerinin [yaprakta klorofil miktarı (SPAD), yaş ağırlık, kuru ağırlık, yaprak oransal su kapsamı ve yaprakta stoma yoğunluğu] belirlenmesi için ölçümler yapılmıştır.

3 ayrı lokasyondan hasatları yapılan ve laboratuvara getirilen meyve örneklerinden her taksona ait 10'ar adet meyve seçilerek bir meyve ağırlıkları (g) ve meyve eti ağırlıkları (g) $0.001 \mathrm{~g}$ duyarlılıkla tartım yapan hassas terazide tek tek tartılmış ve değerler kaydedilmiş, meyve en ve boy ölçümleri, $0.01 \mathrm{~mm}$ duyarlılıkla ölçüm yapan dijital kumpas kullanılarak yapılmış, meyvede çekirdek sayıları ise adet olarak belirlenmiştir.

Yapraklardaki klorofil miktarları sürgün ucundan geriye doğru 2. veya 4. yaprakçık üzerinden SPAD-502 Plus (Konica Minolta Optics, Inc. Tokyo/Japan) cihazı ile ölçülerek SPAD değeri belirlenmiştir (Khan ve ark., 2004).

Yaprak yaş/kuru ve turgor ağırlıkları her taksonun bulunduğu saksılardan alınan yaprak örnekleri ile belirlenmiştir. Yaş ağırlıklar (YA) 3 tekerrürde belirlendikten sonra yaprak örnekleri 24 saat $100 \mathrm{ml}$ saf su içeren petri kaplarında bekletilmiş ve turgor ağırlıkları (TA) tespit edilmiştir. Daha sonra yaprakların kuru ağırlığının (KA) belirlenmesi için yapraklar 48 saat $65^{\circ} \mathrm{C}^{\prime}$ de bekletilmiştir.

$\mathrm{Bu}$ veriler ışığında yaprak oransal su kapsamı (YOSK) $[(Y A-K A) /(T A-K A) \quad x \quad 100]$ formülü ile 
hesaplanmıştır (Sanchez ve ark., 2004; Doğan, 2018). Stoma yoğunluğunun belirlenmesinde

Tırnak Cilası Yöntemi kullanılmıştır (Elçi, 1994; Odabaşıŏlu, 2020). Yapraklarda belirlenmiş noktalara tırnak cilası, ince bir kat halinde sürülmüş ve 15-20 dk kuruması beklenmiştir. Her kalıpta 3 farklı görüş alanı incelenmiş olup görüş alanında tespit edilen stomaların sayısı; $1 \mathrm{~mm}^{2}$ alana uyarlanarak belirlenmiş, sayımlar MShot-

1.3.10. bilgisayar programında yapılmıştır.
Ortalamaların karşılaştırılmasında

LSD testi kullanılmıştır.

\section{Araştırma Bulguları ve Tartışma}

Bitkisel materyal olarak kullanılan taksonların bilimsel, Türkçe, yöresel adları, çiçek renkleri, taç yaprak durumları ve çiçeklenme zamanları Çizelge 1 'de verilmiştir.

Çizelge 1. Bitkisel materyalin genel özellikleri

Table 1. General characteristics of plant material

\begin{tabular}{|c|c|c|c|c|c|}
\hline $\begin{array}{l}\text { Bilimsel Adı } \\
\text { Scientific Name }\end{array}$ & $\begin{array}{l}\text { Türkçe Adı } \\
\text { Turkish Name }\end{array}$ & $\begin{array}{l}\text { Lokal Adı } \\
\text { Local Name }\end{array}$ & $\begin{array}{l}\text { Çiçek Rengi } \\
\text { Flower Color }\end{array}$ & $\begin{array}{l}\text { Çiçek Tipi } \\
\text { Flower Type }\end{array}$ & $\begin{array}{l}\text { Çiçeklenme } \\
\text { Zamanı } \\
\text { Flowering } \\
\text { Time }\end{array}$ \\
\hline R. $a l b a$ & Beyazgül & $\begin{array}{l}\text { Beyazgül, Kızanlık Gül, Sakız Gülü, } \\
\text { Tiryandafil (Özçelik ve Koca,2021) }\end{array}$ & Beyaz & Yarı Katmerli & $\begin{array}{l}\text { Haziran- } \\
\text { Temmuz }\end{array}$ \\
\hline R. canina & Kuşburnu & $\begin{array}{c}\text { 'yabangülü', 'şilan', 'deligül', 'gülburnu', } \\
\text { 'gülelması', 'itburnu' (Işık ve Kocamaz, } \\
\text { 1992; Baytop, 1999; Güneş ve Şen, 2001; } \\
\text { Özçelik, 2010; Orhan ve Hartevioğlu, } \\
\text { 2013; Özçelik, 2013; Özçelik ve Koca, } \\
\text { 2021) }\end{array}$ & Açık Pembe & Yalınkat & $\begin{array}{l}\text { Mayıs- } \\
\text { Haziran }\end{array}$ \\
\hline $\begin{array}{l}\text { R. heckeliana } \\
\text { subsp. } \\
\text { vanheurckiana }\end{array}$ & Şurubi Gül & Şuribi (Alp, 2007) & Pembe & Yalınkat & $\begin{array}{l}\text { Mayıs- } \\
\text { Haziran }\end{array}$ \\
\hline R. hemisphaerica & Çardak Gülü & Sarı Gül (Alp, 2007) & Sarı & Yalınkat & $\begin{array}{l}\text { Mayıs- } \\
\text { Haziran }\end{array}$ \\
\hline $\begin{array}{l}R . \quad \text { odorata } \\
\text { 'Louis XIV' }\end{array}$ & Halfeti Gülü & Halfeti Gülü (Anonim, 2021) & Bordo & Yarı katmerli & $\begin{array}{l}\text { Mayıs- } \\
\text { Temmuz }\end{array}$ \\
\hline R. pisiformis & Hoşap Gülü & $\begin{array}{c}\text { Hoşap Gülü (Alp, 2007), Nazarlık Gül } \\
\text { (Özçelik ve Koca, 2021) }\end{array}$ & Koyu Pembe & Yalınkat & $\begin{array}{l}\text { Mayıs- } \\
\text { Haziran }\end{array}$ \\
\hline R. damascena & Reçellik Gül & $\begin{array}{l}\text { Yağ Gülü (Alp, 2007), Isparta Gülü, } \\
\text { Kazanlık Gül, Misk Gülü (Özçelik ve Koca, } \\
\text { 2021) }\end{array}$ & Açık Kırmızı & Katmerli & $\begin{array}{l}\text { Haziran- } \\
\text { Temmuz }\end{array}$ \\
\hline $\begin{array}{l}\text { R. chinensis } \\
\text { 'Old Blush' }\end{array}$ & Old Blush & Çin Pembesi, Bengal Gülü & Açık Pembe & Yarı Katmerli & $\begin{array}{l}\text { Mayıs- } \\
\text { Haziran }\end{array}$ \\
\hline R. foetida & Sarı Gül & $\begin{array}{l}\text { Van Sarı Gülü (Alp, 2007), Çalı Gülü, } \\
\text { Şilan, Kanarya Gülü (Özçelik ve Koca, } \\
\text { 2021) }\end{array}$ & Sarı & Katmerli & $\begin{array}{l}\text { Haziran- } \\
\text { Temmuz }\end{array}$ \\
\hline
\end{tabular}

Pomolojik analiz verileri (meyve ağırlığı, meyve boyu, meyve eni, çekirdek sayısı, meyve et ağırlığı ve meyve görüntüleri) Çizelge 2'de verilmiştir.

Pomolojik analizlerde, meyve ağırlığı, meyve boyu, meyve eni, çekirdek sayısı ve meyve et ağırlığı ortalama değerleri arasındaki farklar istatistiki bakımdan $\% 5$ düzeyinde önemli bulunmuştur. Meyve ağırlığı bakımından; R. alba ortalama $3.25 \mathrm{~g}$ ile en ağır, $R$. pisiformis $0.13 \mathrm{~g}$ ile en hafif meyvelere sahip iken, Halfeti Gülü ortalama $1.00 \mathrm{~g}$ değeri ile 6.sırada yer almıştır.
Meyve eti ağırlığında da benzer bulgulara rastlanmıştır.

Meyve boyu bakımından en uzun meyve $R$. alba (22.48 mm), en kısa meyve R. pisiformis (7.36 $\mathrm{mm}$ ) olarak belirlenmiştir. Halfeti Gülü bu parametrede 8.sırada yer almıştır. Meyve eni değerleri incelendiğinde, en geniş meyve $R$. foetida $(18.87 \mathrm{~mm})$, en dar çaplı meyve ise $R$. pisiformis $(7.14 \mathrm{~mm})$ olarak belirlenmiştir. Halfeti Gülü meyve eni bakımından 7.sırada yer almıştır. 
Çizelge 2. Araştırmada incelenen taksonların pomolojik özellikleri

Table 2. Pomological characteristics of taxa examined in the study

\begin{tabular}{|c|c|c|c|c|c|c|}
\hline $\begin{array}{l}\text { Taksonlar } \\
\text { Taxa }\end{array}$ & $\begin{array}{l}\text { Meyve Ağırlığı } \\
\text { (g) } \\
\text { Fruit Weight } \\
\text { (g) }\end{array}$ & $\begin{array}{l}\text { Meyve Boyu } \\
\text { (mm) } \\
\text { Fruit Length } \\
(\mathrm{mm})\end{array}$ & $\begin{array}{l}\text { Meyve Eni } \\
(\mathrm{mm}) \\
\text { Fruit Width } \\
(\mathrm{mm})\end{array}$ & $\begin{array}{l}\text { Çekirdek Sayısı } \\
\text { (adet) } \\
\text { Number of } \\
\text { Seeds (pieces) }\end{array}$ & $\begin{array}{l}\text { Meyve Et } \\
\text { Ağırlığı (g) } \\
\text { Fruit Flesh } \\
\text { Weight }(g)\end{array}$ & $\begin{array}{c}\text { Meyve } \\
\text { Görüntüsü } \\
\text { Fruit Image }\end{array}$ \\
\hline $\begin{array}{l}\text { R. odorata 'Louis } \\
\text { XIV' }\end{array}$ & $1.00 \pm 0.09^{d}$ & $12.80 \pm 1.40^{d}$ & $11.65 \pm 0.62^{e}$ & $1.70 \pm 0.82^{c}$ & $0.85 \pm 0.10^{d}$ & \\
\hline $\begin{array}{l}\text { R. chinensis 'Old } \\
\text { Blush' }\end{array}$ & $1.60 \pm 0.18^{b}$ & $17.49 \pm 1.24^{b}$ & $13.45 \pm 0.79^{d}$ & $2.00 \pm 0.81^{c}$ & $1.44 \pm 0.16^{b}$ & \\
\hline R. canina 'Yıldı' & $1.66 \pm 0.34^{b}$ & $22.18 \pm 1.58^{a}$ & $15.09 \pm 1.59^{c}$ & $18.90 \pm 7.44^{\mathrm{a}}$ & $1.14 \pm 0.40^{c}$ & \\
\hline R. hemisphaerica & $0.75 \pm 0.19^{e}$ & $13.95 \pm 1.00^{d}$ & $13.42 \pm 1.32^{d}$ & $2.89 \pm 2.01^{\mathrm{c}}$ & $0.62 \pm 0.18^{e}$ & \\
\hline R. pisiformis & $0.13 \pm 0.02^{\mathrm{g}}$ & $7.36 \pm 0.71^{\mathrm{e}}$ & $7.14 \pm 0.66^{f}$ & $14.40 \pm 4.00^{b}$ & $0.07 \pm 0.01^{f}$ & \\
\hline R. foetida & $1.68 \pm 0.33^{b}$ & $13.14 \pm 1.23^{d}$ & $18.87 \pm 1.40^{\mathrm{a}}$ & $0.00 \pm 0.00^{c}$ & $1.48 \pm 0.27^{b}$ & \\
\hline R. heckeliana & $0.36 \pm 0.08^{f}$ & $13.89 \pm 1.18^{\mathrm{d}}$ & $8.18 \pm 1.02^{f}$ & $2.30 \pm 1.94^{c}$ & $0.26 \pm 0.08^{f}$ & \\
\hline R. $a l b a$ & $3.25 \pm 0.45^{\mathrm{a}}$ & $22.48 \pm 1.44^{\mathrm{a}}$ & $17.60 \pm 1.46^{b}$ & $2.80 \pm 1.22^{c}$ & $2.62 \pm 0.35^{a}$ & \\
\hline R. damascena & $1.32 \pm 0.39^{c}$ & $16.16 \pm 2.11^{c}$ & $13.66 \pm 1.47^{d}$ & $2.50 \pm 1.84^{c}$ & $1.01 \pm 0.29^{\mathrm{cd}}$ & \\
\hline LSD (\%5) & 0.245 & 1.223 & 1.067 & 2.947 & 0.218 & \\
\hline
\end{tabular}

Meyve başına en çok çekirdeğe sahip takson R.canina 'Yıldı' (18.90 adet) olurken, R. foetida'dan alınan meyvelerin partenokarpik olduğu belirlenmiştir. Halfeti Gülü meyve başına ortalama
1.70 adet çekirdek sayısı ile 8 . sırada yer almıştır.

Söz konusu parametrelerin grafik gösterimleri Şekil 1 ve 2'de verilmiştir.

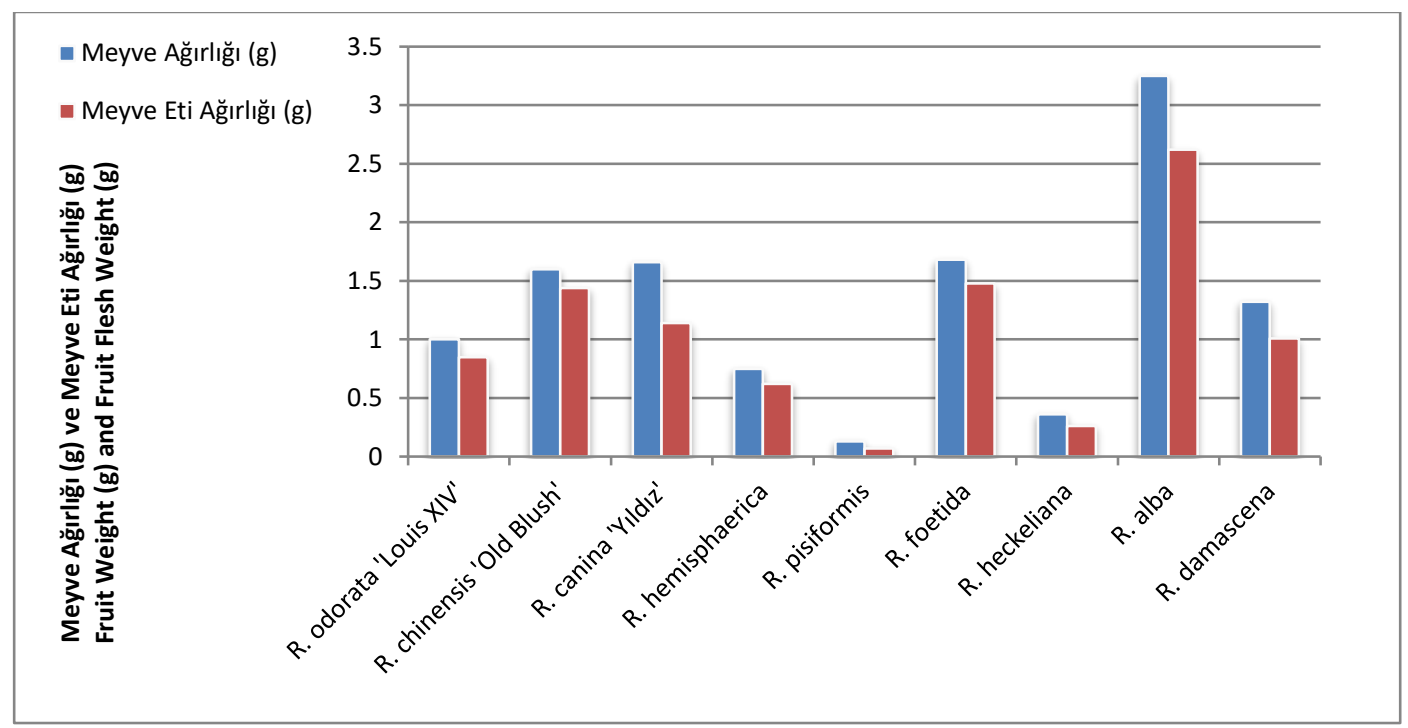

Şekil 1. Çalışılan gül taksonların meyve ağırlığı ve meyve eti ağırıkları

Figure 1. Fruit weight and flesh weight of the studied rose taxa 


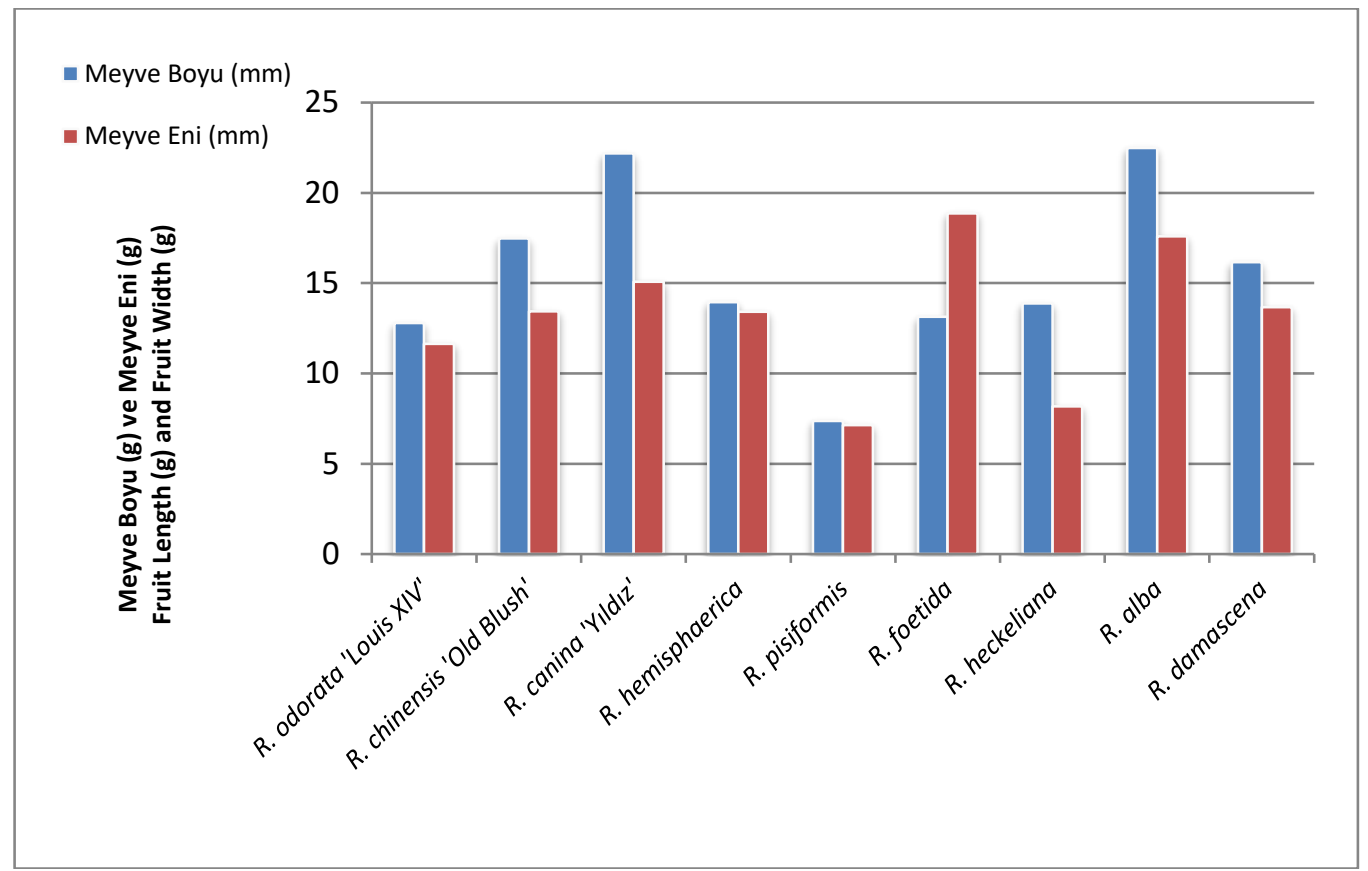

Şekil 2. Çalışılan gül taksonların meyve en ve boy değerleri

Figure 2. Fruit width and height values of the studied rose taxa

Taksonların bazı fizyolojik analiz verileri (yaprak içeriği) Çizelge 3'te verilmiştir. oransal su kapsamı, stoma yoğunluğu ve klorofil

Çizelge 3. Çalışılan gül taksonlarının fizyolojik özellikleri

Table 3. Physiological properties of studied rose taxa

$\begin{array}{cccc} & \text { YOSK } & \text { Stoma Yoğunluğu } & \text { Klorofil İçeriği } \\ \text { Taksonlar } & \text { RWC Rate } & \left(\text { adet } \mathrm{mm}^{-2}\right) & \text { Chlorophyll Content } \\ \text { Taxa } & (\%) & \text { Stoma Density } & \left(p c s \mathrm{~mm}^{-2}\right)\end{array}$

\begin{tabular}{|c|c|c|c|}
\hline R. odorata 'Louis XIV' & $40.30 \pm 4.85^{c}$ & $188.81 \pm 7.01^{\text {cde }}$ & $42.18 \pm 6.99^{\mathrm{ab}}$ \\
\hline R. chinensis 'Old Blush' & $75.12 \pm 6.74^{\mathrm{a}}$ & $240.62 \pm 7.05^{b c}$ & $44.46 \pm 1.76^{a}$ \\
\hline R. canina 'Yıldız' & $72.98 \pm 7.96^{a}$ & $175.09 \pm 6.75^{\mathrm{bcd}}$ & $39.00 \pm 1.42^{b}$ \\
\hline R. hemisphaerica & $55.67 \pm 5.13^{b}$ & $268.53 \pm 9.51^{b}$ & $30.24 \pm 1.25^{\mathrm{de}}$ \\
\hline R. pisiformis & $25.49 \pm 0.85^{d}$ & $169.50 \pm 7.56^{\mathrm{e}}$ & $34.36 \pm 2.44^{c}$ \\
\hline R. foetida & $74.21 \pm 5.79^{a}$ & $275.39 \pm 4.77^{b}$ & $28.32 \pm 1.39^{\mathrm{e}}$ \\
\hline R. heckeliana & $25.84 \pm 3.24^{d}$ & $208.12 \pm 11.82^{\text {cde }}$ & $32.84 \pm 1.82^{c d}$ \\
\hline R. alba & $42.81 \pm 3.28^{c}$ & $180.95 \pm 6.75^{\text {de }}$ & $34.78 \pm 2.61^{c}$ \\
\hline R. damascena & $30.68 \pm 5.68^{c d}$ & $335.06 \pm 8.97^{a}$ & $40.88 \pm 4.09^{a b}$ \\
\hline LSD (\%5) & 12.658 & 12.943 & 4.028 \\
\hline
\end{tabular}

Araştırma materyalini oluşturan bitkilerin yaprak oransal su kapsamı yüzdeleri istatistiksel bakımdan önemli bulunmuştur. 'Old Blush' (75.12\%), 'Yıldız' (72.98\%) ve 'Sarıgül' (74.21\%) taksonları en yüksek yüzdeye sahip iken 'Hoşap Gülü' (25.49\%) ve 'Şurubi Gül' (25.84\%) en düşük yüzdeye sahiplerdir (Şekil 3). Çekiç (2004), Semida ve ark. (2015) ve Doğan (2018) benzer çalışmalarında abiyotik stres faktörlerinin etkileri ile yaprak oransal su kapsamının azaldığını belirtmişlerdir. 


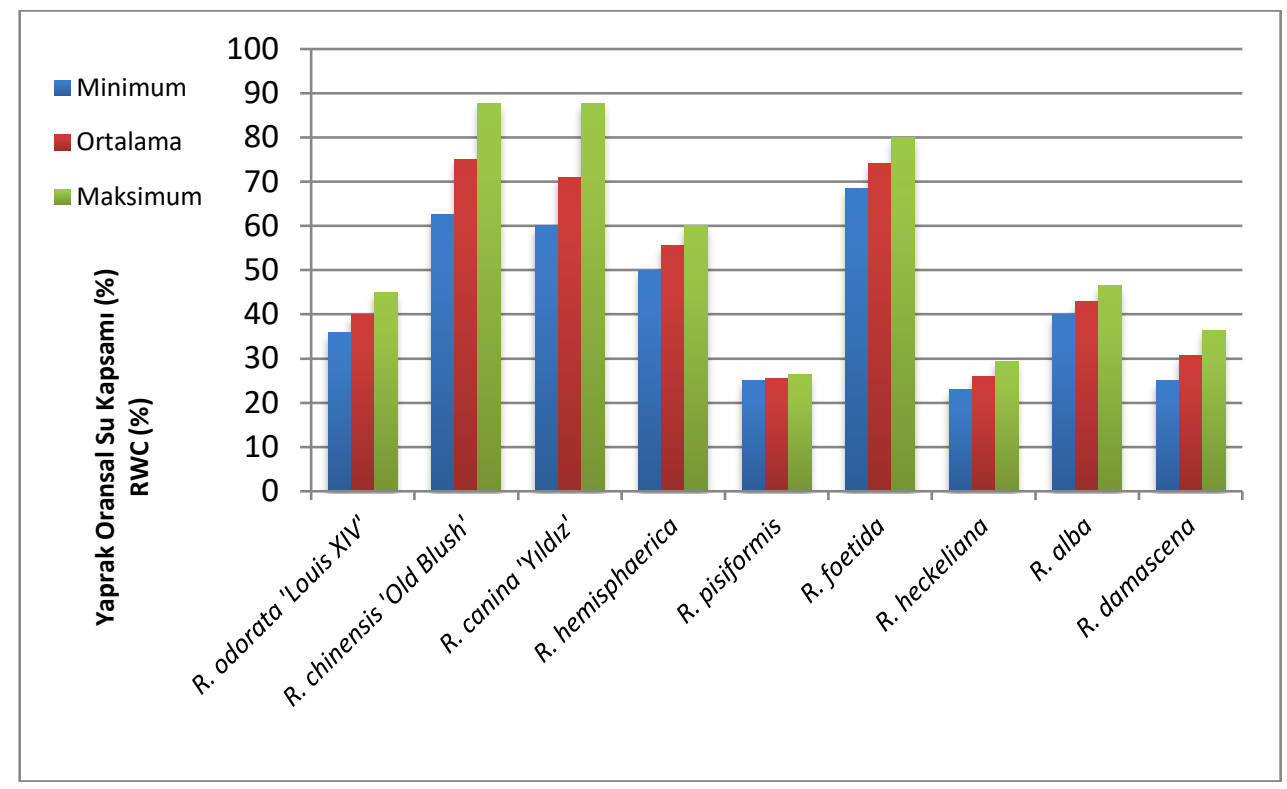

Şekil 3. Çalışılan gül taksonlarına göre yaprak oransal su kapsamları (\%)

Figure 3. Leaf proportional water content according to studied rose taxa (\%)

Özden (2013), sıcaklığın en yüksek ölçüldüğü dönemlerde Halfeti Gülü'ndeki antosiyanin miktarının azaldığını ve yüksek sıcaklıkların renk pigmentlerinin sentezinin azalmasına veya pigmentlerin parçalanmasına sebep olduğunu belirtmiştir. Ayrıca bitkinin geç sonbahar döneminde siyah renk kazanması, bitkinin çevre koşullarına uyumu açısından fizyolojik bir tepki olarak değerlendirilebilir. Sıcaklık stresi bitkide bu şekilde bir etki yaparken, Halfeti Gülü'ünün koyu renk aldığı lokasyonda YOSK oranının düşük bulunması (40.30\%) dikkat çekicidir. Halfeti Gülü bitkisinin sadece belli bir lokasyonda 'koyu siyah' taç yaprak rengi alması aynı zamanda YOSK oranının düşük çıkması da abiyotik stres koşulları ile ilişkilendirilebilmektedir.

Incelenen türlerde stomaların genel olarak yaprakların alt yüzeyinde (hipostomatik) olduğu tespit edilmiştir. Kuşburnu grubu içerisindeki bitkilerin stoma yoğunluğu bakımından birbirlerinden istatistiksel olarak \%5 önem düzeyinde farklılık gösterdikleri saptanmıştır. Bu bağlamda en yüksek stoma yoğunluğu $R$. damascena'da (335.06 adet $\mathrm{mm}^{-2}$ ), en düşük stoma yoğunluğu ise $R$. pisiformis'te (169.50 adet $\mathrm{mm}^{-2}$ ) saptanmıştır (Şekil 4). Elde edilen sonuçlara göre; en yüksek stoma yoğunluğu $R$. damascena'da belirlenmiş ve bu bağlamda ilgili veri benzerlik göstermesine rağmen Şanlıurfa koşullarında en yüksek değer ortalaması 335.06 adet $\mathrm{mm}^{-2}$ olarak bulunurken, Van ekolojisinde en yüksek ortalama değer 290.21 adet $\mathrm{mm}^{-2}$ olarak belirtilmiştir. Halfeti Gülü'de ortalama 188.81 adet $\mathrm{mm}^{-2}$ stoma sayısı ile diğer taksonlara nazaran düşük bir değer almıştır (Alp ve ark., 2016).

Çağlar ve ark. (2004), iki farklı lokasyonda (Kahramanmaraş ve Hatay) yetişen Juglans regia L. genotiplerinde yaptıkları çalışmalarda, stoma yoğunluklarının yükselti ve sıcaklık değerlerine göre değişiklik gösterdiklerini belirtmişlerdir. Bu bağlamda; Van ekolojisine göre daha düşük rakımda bulunan Şanlıurfa'da stoma değerlerinin farklılık göstermesi bu savı desteklemektedir. Ayrıca Halfeti Gülü'ün düşük stoma yoğunluğu değerleri bulunduğu ekolojide farklı taç yaprak rengi alması ile ilişkilendirilebilmektedir.

Alp ve ark. (2016), üç taksonda [R. damascena (290.21adet $\left.\mathrm{mm}^{-2}\right), R$. foetida (237.26 adet $\mathrm{mm}^{-2}$ ), $R$. canina (134.30 adet $\left.\mathrm{mm}^{-2}\right)$ ] bulduğu değerler ile Şanlıurfa koşullarında bulunan değerler [R. damascena (335.06adet $\mathrm{mm}^{-2}$ ), R. foetida (275.39 adet $\mathrm{mm}^{-2}$ ), $R$. canina (175.09adet $\mathrm{mm}^{-2}$ )] nisbi ve sıralama olarak birbiri ile uyuşmaktadır. 


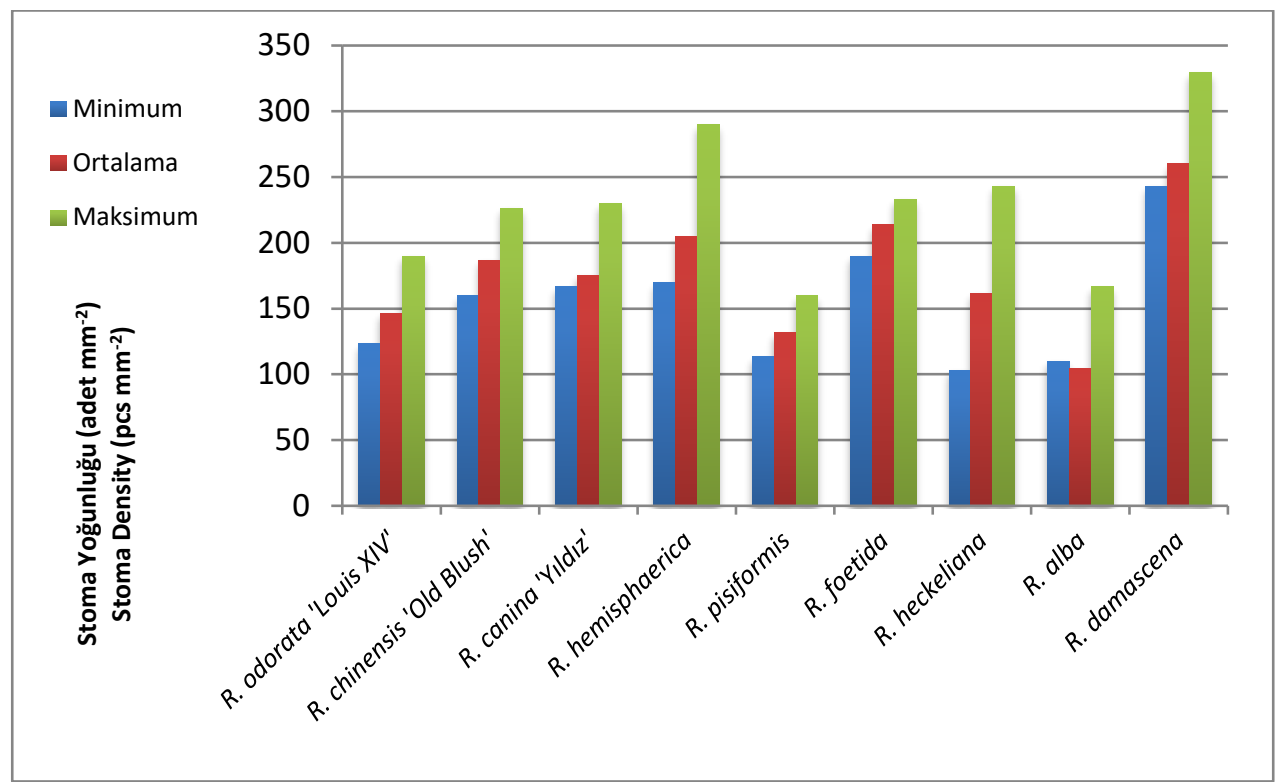

Şekil 4. Çalışılan gül taksonlarına göre stoma yoğunlukları(adet $\mathrm{mm}^{-2}$ )

Figure 4. Stoma densities according to the studied rose taxa (pieces $\mathrm{mm}^{-2}$ )

Analiz sonuçlarına göre; en yüksek klorofil içeriği R. chinensis 'Old Blush”'ta (44.46), en düşük klorofil içeriği ise R.foetida'da (28.32) gözlemlenmiştir. Bitkiler için hayati öneme sahip olan klorofil, fotosentezin ana etken maddesidir ve bitkideki klorofil miktarı, başta ekolojik koşullara ve farklı taksonlara göre çeşitlilik göstermektedir. Ayrıca Kazaz ve ark. (2010), Chrysanthemum morifolium Ramat. bitkisinde gün uzunluğu ile klorofil içeriği arasındaki ilişkiyi incelediği çalışmalarında çiçek, gövde uzunluğu, gövde çapı ve gövde başına çiçek sayıları ve klorofil a ve b içerikleri gibi parametrelerin gün uzunluğundan etkilendiği sonucuna ulaşmışlardır.

Araştırma kapsamında Şanlıurfa koşullarına adapte olan Halfeti Gülü (42.18) ve 'Old Blush' (44.46) taksonları en yüksek klorofil içeriğine sahip olarak bulunmuşlardır. Tokat lokasyonundan temin edilen 'Yıldız' çeşidi de ortalamaya göre optimal klorofil içeriği gösterirken, Yağ Gülü ( $R$. damascena) dışında Van Gölü ekolojisinden temin edilen taksonlarda düşük değerler saptanmıştır (Şekil 5).

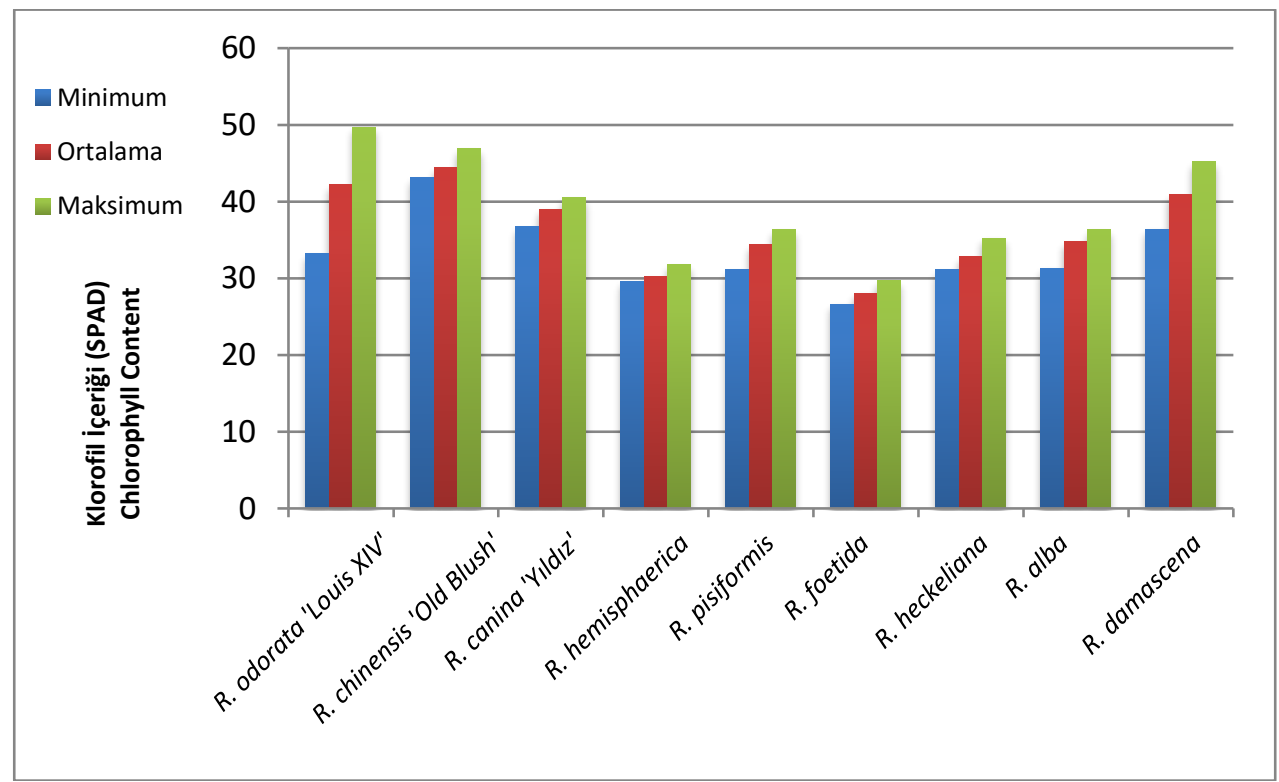

Şekil 5. Çalışılan gül taksonlarına göre klorofil içerikleri (SPAD)

Figure 5. Chlorophyll contents (SPAD) according to the studied rose taxa

Yapılan pomolojik ve fizyolojik analizler neticesinde, Halfeti Gülü bitkisinin bölge için önemli gül/kuşburnu taksonları olabilecek bitkiler ile karşılaştırması yapılmıştır. Halfeti Gülü'nün meyve ağırlığı, meyve eni, meyve boyu ve çekirdek sayıları gibi pomolojik, YOSK, stoma 
yoğunluğu ve klorofil içeriği gibi fizyolojik veriler diğer 8 gül taksonunun ortalaması ile de karşılaştırılmıştır (Şekil 6). Karşılaştırma neticesinde Halfeti Gülü'nün, ortalama klorofil içeriği (SPAD) bakımından diğer taksonlardan yüksek, diğer parametrelerde ise ortalamanın altında değerler aldığı belirlenmiştir.

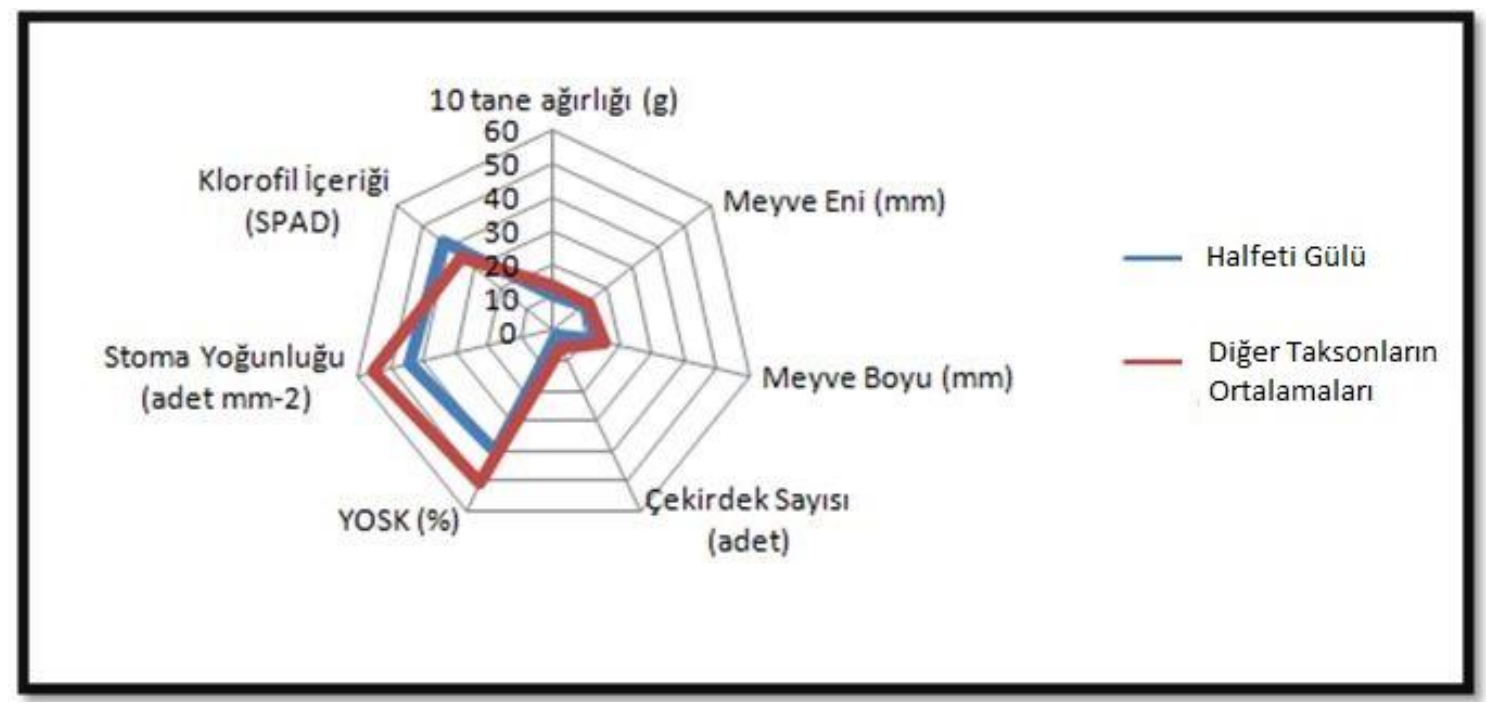

Şekil 6. Halfeti Gülü’nün pomolojik ve fizyolojik verilerinin çalışılan diğer taksonlar ile karşılaştırılması

Figure 6. Comparison of pomological and physiological data of Halfeti Rose with other studied taxa

Yeryüzünde antropojenik etkiler nedeni ile yaşanan hızlı değişim sürecinde doğa birçok yönden olumsuz etkilenmekte, ekolojik dengede bozulmalar meydana gelmektedir. Bu bağlamda söz konusu etkilerden en fazla muzdarip olan bitkilerin sağlığı ve peyzaj planlama çalışmalarında sürdürülebilir kullanımı ile ilgili çalışmalar önem kazanmıştır. Odunsu peyzaj ve süs bitkilerinde; klorofil içeriği, stoma yoğunluğu, yaprak oransal su kapsamı gibi fizyolojik verilerin belirlenmesi bitkinin su stresinin, soğuğa/kuraklığa toleransının ve ozon hasarının belirlenmesi gibi birçok uygulama alanında kullanılabilmektedir.

Peyzaj planlama ve plantasyon çalışmalarında; bitkilerin ekolojik özellikleri ve kullanımdaki amacı da büyük önem taşımaktadır. Bitkilerin lokal ekolojiye adaptasyonunun ve peyzaj kullanım değerlerinin ortaya konması için fizyolojik veriler önem taşımaktadır. Bitkilerin farklı özelliklerinin belirlenmesi neticesinde bitki kullanımlarında kentsel peyzaja katkı sağlayacağı, sürdürülebilir bir yapının tesis edilebileceği düşünülmektedir (Hatipoğlu ve Ak, 2018; 2020).

Türkiye'nin süs bitkileri yetiştiriciliği konusunda öncü ülkelerden biri olması söz konusu kaynakları koruyup, tüm bileşenlerin bir arada çalıştığı, sürdürülebilir stratejilerin belirlenmesi ile mümkün olabilecektir (Kazaz ve ark., 2015). Gül yetiştiriciliğinin sürdürülebilirliği için ticari olarak gülcülüğün sorunlarına yönelik çözüm önerileri artırılmalı, önemli çeşit/tiplerin hem uluslararası hem de ulusal arenada pazarlanması sağlanmalıdır. Bu hususta çiftçilere daha fazla teknik bilgi ve teknik yardım sağlanmalıdır (Gül ve ark., 2015).

Kuşburnu bitkileri kimi zaman kesilerek yakacak olarak kullanılmakta, meyveleri bilinçli toplanmamakta ve bu kaynaklarının israfına neden olmaktadır (Güneş ve Şen, 2001). Bunun aksine günümüzde hızla artan nüfusun besin maddesi ihtiyacını karşılamak için tarımsal üretimin sürekli artırılması ve ürünün çeşitlendirilmesi gibi önemli olgular sağlanarak sürdürülebilir uygulamaların yapılması gerekmektedir.

Sera koşullarında yetiştirilen Rosa L. taksonlarının yaprak morfoloji parametrelerinin tür bazında birbirinden farklı olduğu ve stoma yoğunluklarının genetik farklılıklar ile ilişkili olmasına karşın ekolojik koşullardan da etkilenebileceği göz önünde bulundurulmalıdır (Zieliński ve ark, 2010). Aynı zamanda stoma ölçüm değerlerinin abiyotik stres faktörlerine göre bitkilerde değişim gösterdiğini bildiren 
literatürlerin bulunması; gül/kuşburnu taksonlarında da bu tip değişimlerin gözlemleneceğini doğrulamaktadır. Odunsu peyzaj bitkilerinde veya kültür bitkilerinde, çeşitlere ve yetişme koşullarına göre bitki-su dengesinin kontrolü açısından stoma yoğunluğunun saptanması önemlidir (Alp ve ark., 2016). Bununla birlikte kuraklık stresi çalışmalarında önemli rol oynayan stomaların yoğunluğu değerlerinin saptanması Şanlıurfa gibi yarı-kurak iklim koşullarını intiva eden yerlerde bitkisel kullanım için son derece önemlidir.

\section{Sonuç ve Öneriler}

Dünyada geniş bir yayılış alanına sahip olan Rosa türleri, son yıllarda yapılan çalışmalarla dikkat çekmeye başlamıştır. Türkiye, kuşburnu gen kaynakları bakımından zengindir. Son yıllarda popülerliği artan ve 2021 yılı itibari ile coğrafi işaret alan Halfeti Gülü'nün meyve özellikleri ile ilgili bir yayına rastlanmamıştır. Gülcülük üzerine verilen bilgilerin netleşmesi için teknik terimlerin ve anlamlarının bilinmesine ihtiyaç duyulmuş ve bu konuda belirlenen yeni tanımların gül terimlerine ilave edilmesi amaçlanmaktadır.

Çalışmada materyal olarak seçilen gül taksonlarının pomolojik özelliklerinin İran-Turan Fitocoğrafik Bölgesi'nde yayılış gösteren $R$. hemisphaerica, $R$. canina 'Yıldız', R. pisiformis, $R$. foetida, $R$. heckeliana, $R$. damascena ve $R$. alba gibi farklı türlere bağlı taksonların ve Çin Gülü olarak adlandırılan R.chinensis 'Old Blush' kültivar çeşidinin meyve özelliklerinin karşılaştırılması amaçlanmıştır.

Halfeti Gülü'den elde edilen meyveler ile diğer 8 takson karşılaştırıldığında; meyve ağırlığı, meyve boyu, meyve eni ve meyve et ağırlığı gibi parametrelerde ortalamaya yakın değerler; çekirdek sayısında ise ortalamanın çok altında bir değer elde edilmiştir. Ayrıca Halfeti Gülü fizyolojik özelliklerin belirlenmesi neticesinde diğer taksonlara göre düşük stoma yoğunluğu, yüksek klorofil içeriği ve ortalama YOSK değerleri aldığı sonucuna ulaşılmıştır. Bitkinin fizyolojik özellikler bakımından Şanlıurfa ekolojisine adaptasyonu, bu ekolojide koyu taç yaprak rengi alması, çiçeklenme zamanının uzun olması ve orta düzeyde gelişme kuvvetine sahip habitusu Halfeti Gülü'nün yaygınlaşmasına katkı sağlayabilecek başlıca özellikleridir.

Klorofil içeriği bakımından Halfeti Gülü'ne yakın değerler saptanan Yağ Gülü'nün de Şanlıurfa koşullarına adaptasyonu ve gülcülük kapsamında yetiştiriciliğinin yapılabilirliğinin geniş çaplı araştırılması önerilmektedir. Ayrıca meyvede ağırlık, en ve boy gibi parametrelerde diğer türlere nazaran yüksek değerler bulunan ve Şanlıurfa koşullarında erken bir sürede meyve vermeye başlayan $R$. alba türünün de alternatif bir tarımsal ürün olarak değerlendirilebileceği düşünülmektedir.

Sonuç olarak; bulunduğu ekolojik koşullara adaptasyon sağlayan güller estetik görünümleri ve fonksiyonel etkileri (erozyon önleme, peyzaj onarım çalışmaları vs.) ile kullanılabilmektedir. Özellikle şehirlerarası yollarda yamaç alanlarda kullanılabilmektedir. Üzerinde çalışılan gül taksonlarının meyveleri ile bir görsellik sağlanırsa ve meyvelerinin değeri anlaşılır ise yöre halkı bu bitkileri benimser ve sürdürülebilir bir kullanım sağlanabilir. Fizyolojik özelliklerin belirlenmesinde elde edilen veriler, sera koşullarında ulaşılan değerlerdir. Bu bakımdan aynı ekolojide de pomolojik analizlerin yapılması ve söz konusu bitkilerin genetik materyaller olarak değerlendirilmesi önemlidir.

\section{Ekler}

Bu çalışma, Yükseköğretim Kurulu 100/2000 Sürdürülebilir Tarım Projesi ve Harran Üniversitesi Bilimsel Araştırma Projeler Birimi 19248 nolu Doktora Tez Projesi kapsamında desteklenmiş, İbrahim Halil HATiPOĞLU'nun Doktora tez çalışmasının bir kısmından oluşturulmuştur.

Çıkar Çatışması: Makale yazarları, aralarında herhangi bir çıkar çatışması olmadığını beyan eder.

Yazar Katkısı: İbrahim Halil HATiPOĞLU; Bekir Erol AK danışmanlığında denemeyi kurmuş, bu 
doğrultuda İbrahim Halil HATiPOĞLU ve Bekir Erol AK veri analizleri ve makale yazım sürecini tamamlamışlardır. Tüm yazarlar çalışmayı birlikte yürütmüş, metnin son halini okumuş ve onaylamışlardır.

\section{Kaynaklar}

Anonim, (2012). 'Yıldız' Kuşburnu Çeşidi (Arı Fidan). http://www.tarim.gov.tr/bugem/ttsm/menu/30/kayi t-listeleri. Erişim tarihi: 16 Haziran 2014.

Anonim, (2015). 'Gerçekcioğlu' Kuşburnu Çeşidi. (http://www.tarim.gov.tr/bugem/ttsm/menu/30/kay it-listeleri) (Meyve ve Asma Çeşit Listesi (Fruit/Vine).

Anonim, (2021). Menşe Adı: Halfeti/Halfeti Siyah Gül. Tescil Ettiren; Halfeti Belediyesi, Tescil Tarihi: 01/03/2021, Tescil No: 684, T.C. Sanayi ve Teknoloji Bakanlığı, Türk Patent Kurumu, Ankara.

Alp Ş. (2007). Van kenti ve çevresindeki geleneksel konut bahçelerinde kullanılan bitki materyalinin belirlenmesi. Yüzüncü Yıl Üniversitesi, Ziraat Fakültesi, Tarım Bilimleri Dergisi (J. Agric. Sci.), 17(1): 1-6.

Alp Ş., Çelik F. \& Keskin N. (2016). Bazı gül ve kuşburnu (Rosa ssp.) stoma özellikleri ve yoğunluğunun görüntü analizi yöntemi ile belirlenmesi. Harran Tarım ve Gıda Bilimleri Dergisi, 20(3), 159-165.

Baytop, T. (1999). Türkiye' de bitkiler ile tedavi. Nobel Yayın Dağıtım, 480s, İstanbul.

Baytop, T.(2001). Türkiye'de eski bahçe gülleri. T.C. Kültür Bakanlığı Yayınları, Yayın No, 2593, Sistem Ofset Basım Yayın Sanayi Ticaret Ltd. Şti. Ankara, 149.

Brummitt, R. K. \& Powell, C.E. (editors) (1992). Authors of plant names "A list of authors of scientific names of plants, with recommended standard form of their names including abbreviations". Royal Botanic Gardens, Kew. 732 p.

Çağlar, S., Sütyemez M.\& Bayazit, S. (2004). Seçilmiş bazı ceviz (Juglans regia) tiplerinin stoma yoğunlukları. Akdeniz Üniversitesi Ziraat Fakültesi Dergisi, 17(2) 169-174.

Çekiç, F.Ö. (2004). Tuz ve ağır metal stresine maruz bırakılan domates bitkisinde bazı fizyolojik parametrelerin ve antioksidant savunma sisteminin incelenmesi. Mersin Üniversitesi Fen Bilimleri Enstitüsü, Yüksek Lisans Tezi, 91s.

Celik, F., Kazankaya, A. \& Ercisli, S. (2009). Fruit characteristics of some selected promising rose hip (Rosa spp.) genotypes from Van region of Turkey. African Journal of Agricultural Research Vol. 4 (3), 236-240.

Doğan, M. (2018). Çilekte kadmiyum toksitesi altındaki bitkiler üzerinde hümik Asit ve silikon etkilerinin incelenmesi. Harran Üniversitesi Fen Bilimleri Enstitüsü, Yüksek Lisans Tezi, 44s.

Elçi, Ş. (1994). Sitogenetikte araştırma yöntemleri ve gözlemler. Yüzüncüyıl Üniversitesi Yayınları, Yayın No:18, Van, 238s.
Ercisli, S. (2005). Rose (Rosa spp.) germplasm resources of Turkey.Genetic Resources and Crop Evolution 52(6):787-795.

Gerçekcioğlu, R., \& Öz Atasever, Ö. (2017). Kuşburnu'nda (Rosa montana Chaix subsp. woronovii (Lonacz) Ö. Nilsson L.) çekirdeksiz meyve oluşumu ve meyve özellikleri üzerine farklı hormon dozlarının etkileri. Bahçe Dergisi Özel Sayı 1(46), 45-52.

Gul, M., Kazaz, S., Baydar, H., Sirikci, B.S., (2015). A Study About Technical, Economical Situation, Problems and Improvement of Oil Rose (Rosa damascena Mill.) in Turkey. Journal of Essential Oil Bearing Plants. TEOP 18 (3):613-626.

Güneş, M. \& Şen, S.M. (2001). Tokat yöresinde doğal olarak yetişen kuşburnularının (Rosa spp.) seleksiyon yoluyla ıslahı üzerine bir araştırma. Bahçe Dergisi, 30 (1-2), 9-16 s.

Hatipoğlu, i.H. \& Ak, B.E. (2018). Kentsel dokuda bitkilendirmenin öneminin Şanlıurfa ili Karaköprü ilçesi örneğinde incelenmesi. ISUEP2018 UluslararasI Kentleşme ve Çevre Sorunları Sempozyumu, 28-30 Haziran 2018, Tam Metin Kitabı, 4, 57-60s.

Hatipoğlu, I.H. \& Ak, B.E. (2020). The importance of landscape architecture and ornamental plants in sustainable cities. Ornamental Plants: With Their Features and Usage Principles (Chapter I), IKSAD Publications, ISBN: 978-625-7687-33-1, p. 3-28, Ankara.

Işık, O. \& Kocamaz, C. (1992). kuşburnu üretiminin önemi ve vegetatif yolla çoğaltma olanakları. Türkiye 1. Ulusal Bahçe Bitkileri Kongresi, 1, 285- 289s.

Karagüzel, Ö., Kazaz, S., Baktır, İ. \& Elinç, Z. (2014). Güllerde ıslah çalışmaları. Süleyman Demirel Üniversitesi Fen Bilimleri Enstitüsü Dergisi, 17(2), 14-17.

Kazaz, S., Askin, M.A., Kilic, S., Ersoy, N., (2010). Effects of day length and daminozide on the flowering, some quality parameters and chlorophyll content of Chrysanthemum morifolium Ramat. Scientific Research and Essays 5(21): 3281-3288.

Kazaz, S., Erken, K., Karagüzel, Ö., Alp, Ş., Öztürk, M., Kaya, A.Ş, Gülbağ, F., Temel, M., Erken, S., Saraç, Y.i.., Elinç, Z., Salman, A. \& Hocagil, M. (2015). Süs bitkileri üretiminde değişimler ve yeni arayışlar. Türkiye Ziraat Mühendisliği VIII. Teknik KongresiTam Metin Kitabı, 645-672.

Khan A., Qureshi R. \& Ahmad N. (2004). Salt tolerance of cotton cultivars in relation to relative growth rate in saline enviroments. International Journal of Agriculture \& Biology, 6(5) 786-787.

Kınık, D.E. \& Çelikel, F.G. (2020). Mikoriza ve Oksin Uygulamalarının Kuşburnu (Rosa canina L.) Çeliklerinin Çoğaltılması Üzerine Etkileri. Uluslararası Tarım ve Yaban Hayatı Bilimleri Dergisi (UTYHBD), 6(1), 1-7.

Korkmaz, M. \& Özçelik, H. (2015). Türkiye güllerinin (Rosa L.) yöresel adları ve yetiştikleri yöreler. Süleyman Demirel Üniversitesi Fen Bilimleri Enstitüsü Dergisi 19(1), 75-82.

Odabaşıoğlu, M.í. (2020). Semi-arid koşullarda farklı anaçlar üzerinde yetiştirilen sofralık üzüm çeşitlerinin verim, kalite ve çekirdek özellikleri ile stoma morfolojilerinin incelenmesi. Harran Üniversitesi Fen Bilimleri Enstitüsü, Doktora Tezi, 315s. 
Orhan, D.D. \& Hartevioğlu, A. (2013). Kuşburnu bitkisinin kimyasal bileşimi ve biyolojik aktiviteleri. Spatula $D D ., 3(1), 23-30 \mathrm{~s}$.

Ozcelik, H. (2013). General appearances of Turkish roses, SDÜ Fen Bilimleri Enstitüsü Dergisi 17(1), 29-42.

Özçelik, H. (2010). Türkiye bahçe güllerine (Rosa L.) sistematik katkılar ve yeni kayıtlar, Ot Sistematik Botanik Derg., 17 (1), 9-42s.

Özçelik, Ş. (2013). Türkiye'de meyve gülcülüğü açısından önemli gül (Rosa L. ) türleri üzerinde araştırmalar. Süleyman Demirel Üniversitesi Fen Bilimleri Enstitüsü, Yüksek Lisans Tezi, 171s.

Özçelik, H. (2018). Türkiye'nin siyahi yediveren güllerinin tanıtımı. KSÜ Tarım ve Doğa Dergisi 21(3); 407-423.

Özçelik, H. \& Koca, A. (2021). Türkiye'nin ekonomik amaçlı gül (Rosa L. spp.) taksonları: Sınıflandırması ve üretimi üzerine çalışmalar. Biological Diversity and Conservation, 14(2), 292-324 s.

Özden, M. (2013). Halfeti Gülü siyah mıdır? Atatürk Bahçe Kültürleri Merkez Araştırma Enstitüsü Müdürlüğü $V$. Süs Bitkileri Kongresi, Tam Metin Kitabı, 219-222.
Özden, A.N., Ak, B.E. \& Özden, M. (2017). Farklı Nar (Punica granatum L.) Çeşitlerinin Pomolojik, Fitokimyasal Özellikleri ve Antioksidan Kapasiteleri. Harran Tarım ve Gıda Bilimleri Dergisi, 21(2): 164-176.

Sanchez, F.J., Andres, E.F., Tenorio, J.L.\& Ayerbe, L. (2004). Growth of epicotyls, turgor maintenance and osmotic adjustment in pea plants (Pisum sativa L.). Field Crops Research, 86 81-90.

Semida, W.M., Rady, M.M., Abdelmageed, T.A., Howladar, S.M.\& Abdelhamid, M.T. (2015). Alleviation of cadmium toxicity in common bean (Phaseolus vulgaris L.) plants by the exogenous application of salicylic acid. Journal of Horticultural Science and Biotechnology, 90(1) 83-91.

Şahin, A. \& Meral, Y. (2012). Türkiye'de coğrafi işaretleme ve yöresel ürünler, Türk Bilimsel Derlemeler Dergisi 5 (2), 88-92.

Zieliński, J., Tomaszewski, D., Guzicka, M.\& Rutrowska IA. (2010). Stomata on the pericarp of species of the genus Rosa L. (Rosaceae). Plant Syst Evol 284:49-55. 